\title{
BREAKING THE SILENCE - IS IT A DREAM?
}

\section{Marike de Witt, Ansie Lessing}

\section{INTRODUCTION}

Though Acquired Immune Deficiency Syndrome (AIDS ) has been with us for years, no problem facing modern society has left so many questions unanswered, or has continued to produce such complex and unexplained issues as those surrounding AIDS and the probable causes of the disease (Cawyer \& Smith-Dupré, 1995; Freeman, 2004). Although society is inundated with campaigns, information systems and organisations involved in the prevention of the illness, thousands of people are still infected with AIDS and their families "are often faced with hostility and ostracism and rejection by their communities, rather than being supported" (Cawyer \& Smith-Dupré, 1995:243; Glick \& Sahn, 2004).

The fear of rejection may be the reason why HIV/AIDS remains an issue shrouded in silence in South Africa, though many people are dying of HIV/AIDS-related diseases. According to Heartbeat (2002), people infected with the disease are still stigmatised and marginalised from their communities and society as a whole (Antle, Wells, Goldie, DeMatteo \& King, 2001; Dawood, Bhagwanjee, Govender \& Chohan, 2006).

\section{THEORETICAL FRAMEWORK}

HIV/AIDS is a clinical medical issue which Santrock (2000) describes as “...a sexually transmitted disease caused by the human immunodeficiency virus (HIV), which destroys the body's immune system". Donald, Lazarus and Lolwana (1997:200) go beyond the medical implications of the disease and state that "[t]his sexually transmitted disease has devastating effects on individuals, unborn children, families, and society as a whole". Once a person is infected, the prognosis in the South African context is most likely illness and death.

Suggestions by agents offering support and counselling are futile because people's HIV/AIDS status is often the best-kept secret in Southern African communities. Suggestions that members should use communication as a healing agent and as a preparatory mechanism for living with AIDS, or as an outlet for expressing emotions and also as a means of changing society, cannot be implemented without identifying the infected. The strong emphasis on specifically feedback and self-disclosure as essential elements for communicating support is still just wishful thinking on the part of researchers (Cawyer \& Smith-Dupré, 1995; Hemphill, 2004).

One may assume that communicating openly about HIV/AIDS often produces highly emotional and negative reactions among members of mainstream society. The effect of these negative responses on persons infected with or caring for an individual with AIDS is powerful and surely contributes to the silence that shrouds the disease (Cawyer \& Smith-Dupré, 1995).

For the infected as well as their families and friends, the results of feeling stigmatised often include avoiding social contact, feeling depressed and anxious, and experiencing reticence to communicate about the effects of HIV/AIDS on their daily lives (Cawyer \& Smith-Dupré, 1995).

Taylor, Falke, Mazel and Hilsberg (in Cawyer \& Smith-Dupré, 1995) propose that counselling and working in groups could be beneficial since such face-to-face interaction helps to "normalise" the effects of a life crisis such as coping with AIDS. It also allows group members 
to recognise fear as a common consequence of a crisis and not as an irrational or obsessive response to it.

As the pandemic of HIV/AIDS is overwhelming in Southern Africa, one may assume that the majority of the population will be affected in one or more ways. Questions like the following may be asked: Should every person know his/her HIV status? Are people prepared to go for voluntary testing? Would infected persons make use of counselling services? When tested, would people prefer to go to their own doctor or would they prefer to be tested by a person they do not know? Should sex partners also be tested? Would people prefer to go alone or to be accompanied when going for testing? Would people share knowledge about their HIV status with somebody?

The literature indicates that "breaking the silence" or sharing a problem expedites the healing process. The research question that arose was therefore: "What are people's perceptions of HIV/AIDS and the various strategies to cope with the illness?"

\section{RESEARCH DESIGN AND METHOD}

The researchers decided on implementing a questionnaire as instrument in a survey to determine the perceptions of a community regarding HIV/AIDS-related issues. The nature of the questions was diverse, ranking from structured to open-ended questions. A four-point Likert scale was used to determine the perceptions of the participants. The researchers administered these questionnaires to gain data on participants' perception of HIV/AIDS and their view of strategies to cope with the illness irrespective of their own HIV/AIDS status.

The researchers chose a mixed-method mode of inquiry, involving a combination of quantitative and qualitative methods (De Vos, in De Vos, Strydom, Fouche \& Delport, 2005; Neuman, 2006). Following an in-depth literature study, the researchers compiled a questionnaire to seek answers to AIDS-related questions and to determine whether people tend to keep their status secret. A number of open-ended questions were also asked to gain rich descriptions and explanations of situational influences regarding people's view of AIDS (Scheurich, 1997) and an explorative, interpretive approach was used for the open-ended part of the questionnaire. The aim of the open-ended questions was to understand the epistemology in a trustworthy way, while accepting that researchers' perceptions of reality do not only vary, but in fact could also differ greatly.

A literature review on confidentiality regarding HIV/AIDS status and counselling was undertaken before compiling the questionnaire. In order to identify potentially unclear instructions and items, the questionnaire was evaluated by an expert in research methods. Items that were unclear because of formulation as well as technical implications regarding data capturing were identified, and the formulation of a number of items was amended.

\section{Sample selection}

For the purpose of the enquiry the population was (because of its accessibility) defined as inhabitants older than 16 years in the rural area of the Giyani district in the Limpopo Province of South Africa, and it included the villages of Lenyeney, Mandlakazi and Nkuwankua (Mouton, 2003; Rossouw, 2003). A convenience sampling was drawn consisting of 258 participants including males, females, professional people, housewives, teenagers and people from poor socio-economic backgrounds The researchers made use of a fieldworker (educationalist specialising in Psychology of Education), who was also involved in community projects, to distribute the questionnaire personally and individually to the participants, and to 
assist with its administration as some respondents in that area had only functional literacy or were not able to read or speak English. The fieldworker also acted as an interpreter where necessary.

The qualitative part of the research comprised a literature study and a questionnaire containing some open-ended questions. The quantitative part of the study entailed the administration of a questionnaire, which also requested information regarding gender, age, ethnic group, home language, area of residence, marital status, religion, qualification and career, and included questions concerning HIV/AIDS-related issues (Cohen, Manion \& Morrison, 2000).

Regarding professional ethics, the researchers validated the following as important for this research (Mouton, 2003): objectivity and integrity regarding research; the way the data were recorded; the ethical principles underlying publication of the findings; and participants' awareness of the purpose of the findings, though the survey was anonymous. Participants also had the choice to participate and could withdraw whenever they wanted to.

According to Guba (in Poggenpoel, 1998) as well as Mouton (2003), trustworthiness of the results of the qualitative section of the research was facilitated by using a dependable and reliable, qualified fieldworker, in this case specialising in Psychology of Education. The fieldworker was familiar with the area as well as the language (Shangaan) used by the participants. The researchers set a relationship of trust between the fieldworker and the participants as a high priority. The questionnaire was constructed as an instrument to establish trends and was not designed for extensive numerical treatment of data (Mouton, 2003).

\section{FINDINGS AND DISCUSSION OF RESULTS}

Questions were formulated to obtain the perceptions of a specific community on HIV/AIDSrelated issues. The profile of the participants was as follows: $62.4 \%$ were younger than 20 years of age; $15.9 \%$ were between 20 and 29 years; $11.2 \%$ were between 30 and 39 years; and $10.5 \%$ were older than 40 . In terms of gender, $42.6 \%$ of the participants were male and $57.4 \%$ female.

A discussion of the answers obtained from these respondents is provided below.

The statistical data regarding the various questions in the questionnaire are presented in Table 1 to Table 9 and the different aspects dealt with in the questionnaire are dealt with individually in the rest of this section.

Accessibility to medical services seems to be a very important factor in dealing with this phenomenon of HIV/AIDS.

\section{Accessibility to an HIV/AIDS clinic or service}

The content of Table 1 is a reflection of the findings on the question: Do you have access to an HIV/AIDS clinic or service?

TABLE 1

\begin{tabular}{|c|c|c|}
\hline Options & Frequency & Percentage age \\
\hline Valid Yes, easy to access & 128 & 50.4 \\
No, difficult to access & 48 & 18.9 \\
I don't know & 78 & 30.7 \\
Missing from System & 4 & 1.6 \\
\hline Total & $\mathbf{2 5 8}$ & $\mathbf{1 0 0 . 0 0}$ \\
\hline
\end{tabular}


Regarding the question of the accessibility to a clinic or medical service, $50.4 \%$ of the participants indicated that they had access to such facilities, $18.9 \%$ reported difficulty in obtaining access and $30.7 \%$ did not know whether facilities were available. According to the participants, there were very few clinics available in that specific area. The fact that $30.7 \%$ of respondents indicated that they were not aware of the services might indicate that the communities did not have much knowledge of the services available to them, or that the services were not sufficiently visible. Although ignorance about services seems to be a common phenomenon among communities in developing countries (Origo \& Sherr, 2005), the lack of HIV/AIDS clinics or health clinics in the specific area may also contribute to the ignorance of some participants. It is important to note that because of their poverty and the lack of transport, $18.9 \%$ of the participants could not go to the clinics.

The plea that people should know their status to be able to manage the problem of HIV/AIDS leads to the following question.

\section{Knowledge regarding HIV/AIDS status}

The content of Table 2 reflects the findings on the question: Do you think every person should know his/her HIV/AIDS status?

TABLE 2

\begin{tabular}{|c|c|c|}
\hline Options & Frequency & Percentage age \\
\hline Valid Yes & 221 & 87.4 \\
No & 18 & 7.1 \\
Unsure & 14 & 5.5 \\
Missing from System & 5 & 1.9 \\
\hline Total & $\mathbf{2 5 8}$ & $\mathbf{1 0 0 . 0 0}$ \\
\hline
\end{tabular}

It was found that $87.4 \%$ of the respondents felt that every person should know his/her HIV status, while $7.1 \%$ felt that it is not necessary to know one's status. It is surprising that the majority of respondents felt that people should know their HIV status. It is obvious that the pandemic is still shrouded in secrecy in South Africa. Data from a report by the International Center for Research on Women (2002) confirms that the HIV-related stigma is highly complex, dynamic and deeply ingrained, resulting in discrimination. This report also emphasises that a lack of knowledge regarding HIV contributes largely to the problem of stigmatisation (International Center for Research on Women, 2002). It is thus important to note that knowing their status does not imply that the respondents want to share this knowledge with others. In the open-ended questions respondents in the survey expressed the need to know one's HIV/AIDS status to prevent the spread of the disease. A number of respondents (221) believed that one should know one's status, while only 51 of the respondents stated that they had been tested. This seems to reflect an anomaly, as knowing one's status is important in order to avoid living a lie.

\section{Voluntary testing}

Voluntary testing seems a starting point in addressing the problem. The content of Table 3 reflects the findings on the question: Are you prepared to go for voluntary testing? 
TABLE 3

\begin{tabular}{|c|c|c|}
\hline Options & Frequency & Percentage age \\
\hline Valid Yes & 176 & 68.2 \\
No & 62 & 24.0 \\
Unsure & 18 & 7.0 \\
Missing from System & 2 & .8 \\
\hline Total & $\mathbf{2 5 8}$ & $\mathbf{1 0 0 . 0 0}$ \\
\hline
\end{tabular}

On the question of voluntary testing, $68.2 \%$ of respondents indicated that they felt people should go for voluntary testing, while $24 \%$ did not agree and $7 \%$ were unsure. As HIV testing in South Africa is not enforced by law as in other African countries (De Corte, Mazonde \& Darkoh, 2004; Solomon, Van Rooyen, Griesel, Gray, Stein \& Nott, 2004), it is within the right of every individual to decide whether he or she wants to be tested and to be informed about his/her HIV status. Unless this policy changes in South Africa, one can expect that testing will be driven by individual preference. A total of 172 participants answered in the positive, but only 51 of the participants went for testing. From the open-ended questions it was evident that they were afraid of the results and did not want to break the silence.

\section{Voluntary use of counselling services}

It appears from the literature that people regard counselling as crucial in order to manage their HIV/AIDS status. The following question was formulated to address this issue: Are you prepared to go for voluntary HIV/AIDS counselling? Table 4 reflects the findings in this regard.

TABLE 4

\begin{tabular}{|c|c|c|}
\hline Options & Frequency & Percentage age \\
\hline Valid Yes & 178 & 69.0 \\
No & 54 & 20.9 \\
Unsure & 23 & 8.9 \\
Missing from System & 3 & 1.2 \\
\hline Total & $\mathbf{2 5 8}$ & $\mathbf{1 0 0 . 0 0}$ \\
\hline
\end{tabular}

On the question of whether they would make use of counselling services, $69 \%$ of the respondents indicated that they would participate, while $20.9 \%$ felt that they would not make use of counselling services. As Britton (2000) suggests, the therapeutic process may help clients to discover options and make decisions, explore adherence issues and change behaviour, making this a crucial factor in dealing with communities. Stein (1996 in Solomon et al., 2004) reports that the goal of supportive counselling is less useful in an African context than in a Western context. Stein further argues that this avoidance of coping in an African context may be a rational strategic act on the part of HIV-positive people as a prerequisite for ongoing mental and physical health (Solomon et al., 2004).

The availability and preference of medical services also seems to be an issue that should be taken into consideration in any planning regarding the illness. 


\section{Where to go for testing}

It was necessary to determine whether the respondents would prefer to go to their own doctor for voluntary testing or to someone they do not know. The content of Table 5 reflects the findings on the question: If you decide to go for voluntary testing, where would you go?

TABLE 5

\begin{tabular}{|c|c|c|}
\hline Options & Frequency & Percentage age \\
\hline Valid Nearest clinic or doctor & 166 & 64.3 \\
Where nobody knows me & 89 & 34.5 \\
Missing from System & 3 & 1.2 \\
\hline Total & $\mathbf{2 5 8}$ & $\mathbf{1 0 0 . 0 0}$ \\
\hline
\end{tabular}

Altogether $64.3 \%$ of the respondents would prefer to be tested by their own doctor, while $34.5 \%$ indicated that they would prefer to remain anonymous. It seems that the fear of rejection and the possibility of stigmatisation still play a major role in unveiling the status of an HIVinfected person within the Southern African context (Integrated faith-based initiative to treat HIV/AIDS in Mozambique, 2006). In the open questions the respondents expressed their preference to go to their own doctor for practical reasons.

In the open-ended questions the respondents who indicated that they would prefer another doctor or clinic said so because they were afraid that the community would gossip about them.

\section{Testing of sex partners}

The issue of support from and counselling by relatives seems to be obvious in research of this nature. To accommodate this aspect, the following question was asked: Do you think individuals should go alone for voluntary testing, or should sex partners also be tested? The findings are reflected in Table 6.

TABLE 6

\begin{tabular}{|c|c|c|}
\hline Options & Frequency & Percentage age \\
\hline Valid People should be tested individually & 42 & 16.3 \\
Partners should also be tested & 210 & 81.4 \\
Missing from System & 6 & 2.3 \\
\hline Total & $\mathbf{2 5 8}$ & $\mathbf{1 0 0 . 0 0}$ \\
\hline
\end{tabular}

According to a report by Solomon et al. (2004), counselling and a change of behaviour were more positive when partners were included in the testing and counselling. Of the respondents in the survey, $81.4 \%$ wanted their sex partners to be tested as well, while $16.3 \%$ felt that people should be tested individually. Origo and Sherr (2005) emphasise the importance of involving the partners of participants in the research and insisted that partners should be incorporated in all programmes. According to Origo and Sherr (2005), a partner's involvement is often the key to ensuring support for women. USAID (2003) also sees the involvement of partners as crucial in supporting women. According to Ritvo, Willms, Meisner, Brown, Goldman and Sewankambo (2006), HIV/AIDS patients tend to blame their spouses for spreading the infection. From the open-ended questions it was clear that respondents wanted their partners to be tested to confirm trustworthiness. 


\section{Receiving the results of the testing}

Once again the support of family members or relatives can be useful, but it is important to know what people do in fact prefer. The content of Table 7 is a reflection of the findings on the question: Would you prefer to go alone when you receive your HIV test results, or would you prefer to take someone with you?

TABLE 7

\begin{tabular}{|c|c|c|}
\hline Options & Frequency & Percentage age \\
\hline Valid Alone & 134 & 51.9 \\
Take someone with me & 120 & 46.5 \\
Missing from System & 4 & 1.6 \\
\hline Total & $\mathbf{2 5 8}$ & $\mathbf{1 0 0 . 0 0}$ \\
\hline
\end{tabular}

On the question of whether they wanted to be accompanied by someone when receiving their test results, $51.9 \%$ indicated that they would want somebody to go with them, while $46.5 \%$ said that they would prefer to go on their own to receive their results. In the open-ended question the respondents indicated that they could rely on the support of their family. An unexpectedly high percentage of participants indicated that they wanted to be alone, which could be linked to the "culture of silence" about HIV/AIDS status. People may fear stigmatisation and marginalisation (Heartbeat, 2002). It is a positive sign that $48.1 \%$ of the participants realised the value of support.

\section{Secrecy of HIV status}

As this survey was based on confidentiality, a question to address this matter had to be included. The content of Table 8 is a reflection of the findings on the question: If you test HIV positive, would you share the news with somebody, or would you keep it a secret?

TABLE 8

\begin{tabular}{|c|c|c|}
\hline Options & Frequency & Percentage age \\
\hline Valid I would share the news & 198 & 76.7 \\
I would keep the news a secret & 54 & 20.9 \\
Missing from System & 6 & 2.3 \\
\hline Total & $\mathbf{2 5 8}$ & $\mathbf{1 0 0 . 0 0}$ \\
\hline
\end{tabular}

On the question of whether they would share their HIV status, $76.7 \%$ indicated that they would share the news, and $20.9 \%$ thought that they would keep the results of the testing a secret. The issue of confidentiality is a serious matter when working with communities in a Southern African context. This finding of the research, indicating that $76.7 \%$ were willing to share their HIV/AIDS status, seems to contradict the literature regarding HIV/AIDS status in developing countries, where it is indicated that confidentiality is still a contentious issue (Glick \& Sahn, 2004; Solomon et al., 2004; USAID, 2003). Solomon et al. (2004) confirm that people prefer to keep silent, because they fear negative personal and social outcomes. Silence is still enshrouding the diseased and many HIV/AIDS-infected sufferers are living lonely lives without the support of the community. On the other hand, it must be kept in mind that these are perceptions and participants are not always honest with themselves. The respondents indicated that they would share the information regarding their status, yet they are not willing to go for testing. It seems as if the respondents did know what the right thing was to do, but resisted doing so. 


\section{Counselling}

The question on preference for counselling was included as a plea for counselling services if people register a need for it. The content of Table 9 is a reflection of the findings on the question: If you have been tested for HIV before, have you received post-HIV test counselling?

TABLE 9

\begin{tabular}{|c|c|c|}
\hline Options & Frequency & Percentage age \\
\hline Valid I have never been tested before & 195 & 75.6 \\
I was tested without counselling afterwards & 40 & 15.5 \\
Received HIV test counselling afterwards & 11 & 4.3 \\
Missing from System & 12 & 4.7 \\
\hline \multicolumn{1}{c|}{ Total } & $\mathbf{2 5 8}$ & $\mathbf{1 0 0 . 0 0}$ \\
\hline
\end{tabular}

Of the respondents, $75.6 \%$ had not been tested before, while $16.3 \%$ had been tested without receiving any counselling afterwards. Only $4.3 \%$ had received HIV counselling. Counselling and support, not only for the infected but also for the family, are a top priority in HIV/AIDS programmes (De Corte et al., 2004; Origo \& Sherr, 2005). It therefore seems that proper counselling is still lacking in the specific area where the research was done. In analysing this aspect, it became evident that 51 of the 258 (i.e. 19.76\%) respondents had previously been tested for HIV/AIDS. Counselling had been given to 11 of those respondents. These data revealed that $22 \%$ of those who had been tested had received counselling, while $78 \%$ had not received any counselling

Although the majority of respondents felt that every person should know his/her HIV status and go for voluntary testing, $75.6 \%$ of the respondents had not been tested before. The fact that they had not been tested before contradicts this statement that one should know one's own status, and implies that respondents knew that they should determine their HIV status, but were not doing anything to determine it because they were afraid of the outcome. Thus, although not clearly evident from the results, the pandemic may still be shrouded in secrecy in Southern Africa. This conflict in the findings raises the question of whether the legalising of one's HIV/AIDS status is not becoming an important issue for policy-makers in this country, which correlates with recent research done in Africa (Solomon et al., 2004).

\section{CONCLUSION AND RECOMMENDATIONS}

Some of the limitations of the research, as well as the findings, are discussed in this section, and finally recommendations are offered.

The research was limited in scope as it was only done in a certain area. Furthermore, previously standardised questionnaires were not used in the research, and the group was relatively small $(n=258)$. In spite of these limitations and the inability to generalise them, the findings provide valuable information on the perceptions of the participants irrespective of their HIV/AIDS status.

People who are suffering from HIV/AIDS need support to cope with the results and implications of the illness, but according to the literature people tend to keep their HIV status secret. The researchers were concerned about this silence and wanted to determine the general perception of people about HIV/AIDS. A questionnaire was used to gather information to answer the following research question: "What are people's perceptions of HIV/AIDS and the various strategies to cope with the illness?" 
The literature review confirmed that people are not willing to reveal their HIV status, because they fear that they will be stigmatised. People who are HIV-infected, as well as their family and friends, experience emotional and social stress, and the silence prevents them from being supported.

Responses to the questionnaire revealed that the majority of respondents felt that people should know their HIV status, that they should go for voluntary testing, make use of counselling services, be accompanied by someone when receiving the results and share their HIV status with other people. It was also found that only half of the respondents had access to medical services and that the respondents in general preferred to visit their own doctor for the sake of confidentiality and trust, rather than somebody unfamiliar to them.

The importance of counselling is stressed in most programmes, as became evident in the literature used by the researcher for this research. On the question of whether they would make use of counselling services, the majority of respondents indicated that they would participate, while a small number felt that they would not make use of counselling services. Only $25 \%$ of the respondents who had been tested for HIV/AIDS before had received counselling afterwards. This is in accordance with the literature and the findings of Cawyer and SmithDupré (1995) that counselling services seem to be lacking in most programmes implemented in the deep rural areas. Although the study was limited to a specific area in Limpopo Province and thus cannot be generalised to other rural communities, the findings were of great value. The research indicated that people regard breaking the silence about HIV/AIDS status as important and it seems that there is a positive attitude regarding strategies to cope with the illness.

From the findings and conclusions, the following can be recommended: since advocacy campaigns to inform communities on facilities for medical services and counselling seem to be of great importance, they could be utilised to good effect. If facilities are not available in any specific area, the Department of Health should address this need as soon as possible. All people from all communities should be included, irrespective of their HIV/AIDS status.

More specifically, the findings regarding the accessibility of a clinic or medical services in the area where the research was done show that the Department of Health in Limpopo Province should urgently attend to the availability and the accessibility of facilities. Irrespective of whether it is a lack of information on the side of residents or not, it is suggested that the Department of Health should implement advocacy programmes to inform rural communities of the importance of medical facilities in identifying and combating the pandemic.

Since support for people with HIV/AIDS is important, the role of community support groups cannot be over-emphasised and such support groups will have to take responsibility for the establishment of the required support structures. Support structures should assist in providing information on the disease and its implications for family and community life. The dissemination of information could be organised by NGOs, the Department of Health, the Department of Social Development, community leaders and church organisations.

The findings from this research were more positive than expected. However, there is a discrepancy in the participants' perceptions, which may indicate that many of them are living a lie, as they do not know their HIV/AIDS status and do not intend to find out what it is. The researchers admit that the non-HIV status of some of the participants might have influenced the responses. From the research it was found that although more than half the respondents were willing to share their status with other people, many were still unwilling to reveal their status. Thus, it seems that the dream of "breaking the silence" is still not becoming a reality. 


\section{REFERENCE}

ANTLE, B.J., WELlS, L.M., GOLDIE, R.S., DEMATTEO, D. \& KING, S.M. 2001. Challenges of parenting for families living with HIV/AIDS. Social Work, 46(2):59-169.

BRITTON, P.J. 2000. Staying on the roller coaster with clients: implications of the new HIV/AIDS medical treatments for counseling. Journal of Mental Health Counseling, 22(1):85-94.

CAWYER, C.S. \& SMITH-DUPRÉ, A. 1995. Communicating social support: identifying supportive episodes in an HIV/AID support group. Communication Quarterly, (43)3:243358.

COHEN, C., MANION. L. \& MORRISON, K. 2000. Research methods in education ( $5^{\text {th }}$ ed). London: Routledge.

DAWOOD, N., BHAGWANJEE, A., GOVENDER, K. \& CHOHAN, E. 2006. Knowledge, attitudes and sexual practices of adolescents with mild retardation, in relation HIV/AIDS. African Journal of AIDS Research, 5(1):1-10.

DE CORTE, D., MAZONDE, P. \& DARKOH, E. 2004. Introducing ARV therapy in the public sector in Botswana. World Health Organization. Geneva.

DE VOS, A.S. 2005. Combined quantitative and qualitative approach. In: DE VOS, A.S. (ed), STRYDOM, H., FOUCHÉ, C.B. \& DELPORT, C.S.L. Research at grass roots: for the social sciences and human service professions $\left(3^{\text {rd }}\right.$ ed). Pretoria: Van Schaik Publishers: 357-366.

DONALD, D., LAZARUS, S. \& LOLWANA, P. 1997. Educational psychology in social context. Challenges of development, social issues, and special need in southern Africa. Cape Town: Oxford.

FREEMAN, 2004. HIV/AIDS in developing countries. South Africa Journal of Psychology, 34(1):139-159.

GLICK, P. \& SAHN, D.E. 2004. Changes in HIV/AIDS knowledge and testing behavior in Africa. How much and for whom. New York: Cornell University.

HEARTBEAT, V. 2002. Joining Hands. News Letter, 3:1-8.

HEMPHILL, M.L. 2004. Support groups: tools for living well. [Online] Available: http://www.the body.com/asp/marapr04/support_groups.html?m37h.p1.

INTEGRATED FAITH-BASED INITIATIVE TO TREAT HIV/AIDS IN MOZAMBIQUE. 2006. An integrated faith-based initiative to treat HIV/AIDS in Mozambique. [Online] Available: http://www.who.int/hiv/pub/casestudies/dream/en/index.html. [Accessed: 30/08/ 2006.

INTERNATIONAL CENTER FOR RESEARCH ON WOMEN. 2002. Understanding HIVrelated stigma and resulting discrimination in Sub-Sahara Africa. Research Update. Washington.

MOUTON, J. 2003. How to succeed in your master's and doctoral studies. A South African Guide and Resource Book. Pretoria: Van Schaik Publishers.

NEUMAN, LW. 2006. Social research methods. Qualitative and quantitative approaches $\left(4^{\text {th }}\right.$ ed). London: Allyn and Bacon. 
432

ORIGO, D. \& SHERR, L. 2005. Psychosocial support for HIV-infected women in a PMTCT Programme and their families. Word Health Organization. Geneva.

POGGENPOEL, M. 1998. Data analysis in qualitative research. In: DE VOS, A.S. (ed), STRYDOM, H., FOUCHÉ, C.B. \& DELPORT, C.S.L. Research at grass roots: for the social sciences and human service professions $\left(3^{\text {rd }}\right.$ ed). Pretoria: Van Schaik Publishers.

RITVO, P., WILLMS, D., MEISNER, R., BROWN, L., GOLDMAN, A. \& SEWANKAMBO, N. 2006. Vaccine preparedness: lessons from Lyantonde, Uganda. African Journal of AIDS Research, 5(1):11-16.

ROSSOUW, D. (ed) 2003. Intellectual tools: skills for the human sciences $\left(2^{\text {nd }}\right.$ ed). Cape Town: Creda Communications.

SANTROCK, J. 2000. Psychology (6 ${ }^{\text {th }}$ ed). New York: McGraw-Hill.

SCHEURICH, J.J. 1997. Research methods in the postmodern. London: Falmer.

SOLOMON, A., VAN ROOYEN, H., GRIESEL, R. GRAY, D., STEIN, J. \& NOTT, V. 2004. Critical review and analysis of voluntary counselling and testing literature in Africa. Health systems trust. Durban: University of KwaZulu-Natal.

USAID. 2003. Women's experiences for VCT and PMTCT. Report of USAID Technical Meeting. USAID offices of HIV/AIDS. Washington DC.

Acknowledgement: A word of appreciation to the fieldworker, Dr H Baloyi.

Prof Marike W de Witt, Department of Teacher Education; Prof Ansie Lessing, Department of Educational Studies, University of South Africa, Pretoria, South Africa. 